\title{
Performance Enhancement of High Step-up DC-DC Converter to Attain High Efficiency and Low Voltage Stress
}

\author{
Waqas Hassan \\ School of Electrical and \\ Information Engineering \\ The University of Sydney \\ NSW, Australia \\ waqas.hassan@sydney.edu.au
}

\author{
Rasedul Hasan \\ School of Electrical and \\ Information Engineering \\ The University of Sydney \\ NSW, Australia \\ rasedul.hasan@sydney.edu.au
}

\author{
Dylan Dah-Chuan Lu \\ School of Electrical and \\ Data Engineering \\ University of Technology \\ Sydney, Australia \\ dylan.lu@uts.edu.au
}

\author{
Weidong Xiao \\ School of Electrical and \\ Information Engineering \\ The University of Sydney \\ NSW, Australia \\ weidong.xiao@sydney.edu.au
}

\author{
John Long Soon \\ Department of Electrical \\ and Computer Engineering \\ National University of \\ Singapore (NUS) \\ johnlong@nus.edu.sg
}

\begin{abstract}
This study proposes a new high voltage gain and high-efficiency dc-dc converter to interface renewable energy resources into dc nanogrid. The proposed topology is formed by a coupled inductor to achieve high voltage gain and low stress on the active switch. The switch voltage stress is significantly low compared to the output voltage. Thus, efficiency is improved by utilizing a low voltage rating MOSFET. Furthermore, the utilization of couple inductor eliminated the reverse recovery losses of diodes. The converter consists of the least number of components that decrease the overall system cost. The steadystate operation and analysis of the proposed converter are discussed comprehensively. The experimental performance is verified by building and testing a prototype in the laboratory. The experimental results prove the consistency with the theoretical analysis. The converter depicts a peak efficiency of $\mathbf{9 7 . 1 0} \%$ in the laboratory.
\end{abstract}

Keywords-coupled inductor, dc nanogrid, high conversion gain, renewable energy, solar photovoltaic.

\section{INTRODUCTION}

In recent years, renewable energy resources are gaining more popularity as conventional energy sources are depleting due to massive exploitation. The traditional energy sources are causing global warming and other health-related issues that include air pollution and $\mathrm{CO} 2$ emission. Renewable energy resources, for example, solar photovoltaic (PV) and fuel-cells are eco-friendly and sustainable sources of energy [1].

Nanogrid is a small localized integrated energy system consisting of renewable energy resources, such as photovoltaic (PV), for a home or office building. The concept is flourishing with time as it is a simple, reliable, and efficient solution [2]. Moreover, DC nanogrid eliminates the common problems associated with altering current $(\mathrm{AC})$ grid. It also reduces the energy conversion stages thus achieving high efficiency and reliability. The architecture of a DC nanogrid is illustrated in Fig. 1. It contains different power electronic converters to integrate sources and load into high voltage DC bus. The typical voltage of DC bus is $380 \mathrm{~V}$ in DC nanogrid. As renewable energy sources, for example, fuel-cell and solar PV generates a low output voltage. The DC-DC power converter plays a vital role in DC nanogrid. Thus, a DC-DC converter with a high step-up capability is essential to interface different sources.

The classical boost converter can attain a high voltage gain theoretically. However, practically the boost converter is unable to attain high conversion gain and efficiency for a high step-up application. Thus, the solution is not considered fruitful. The researchers have proposed different solutions for attaining high voltage gain. One of them is voltage lift circuits [3]. The utilization of voltage multipliers is an analogous solution. Switched-capacitor or switched-inductor are other popular techniques for attaining high voltage gain [4].
However, the devices suffer from high stresses of current in both aforementioned techniques. The utilization of highfrequency transformer is another method for attaining high gain [5], [6]. Flyback and forward converter are based on this technique. However, the voltage gain is still moderate and mainly depends on the transformer turns ratio. Moreover, the voltage stress on devices in these topologies are high. The use of a transformer in non-isolated fashion is another popular technique, which is also named coupled inductor [7]. The coupled inductor technique has gained popularity as it has shown promising results for high voltage gain applications. However, proper snubber circuits are required to avoid voltage spike on the active switch. The converter without the snubber circuit suffers from a high voltage spike and ringing across the switching node [7]. The snubber circuits are utilized to mitigate these problems [8]. The active snubber circuit realizes zero voltage switching (ZVS) by employing another active switch [9]-[11]. However, cost and complexity are increased. A novel high step-up converter with zero current switching (ZCS) is proposed in [12]. The converter can attain high gain and efficiency meanwhile realizing ZCS without employing extra switch. To further raise the conversion ratio of voltage, the voltage lift circuits can be integrated into the coupled inductor technique [13]-[16]. The concept of multiwinding is also proposed in the literature to further increase the voltage gain and decrease voltage stresses [17]. But it increases system complexity. Furthermore, the switched capacitor and coupled inductor techniques are combined to gain the advantage of both techniques [18]-[20]. The interleaving concept is fruitful for high power applications. It divides the current and thermal stresses on devices; however,

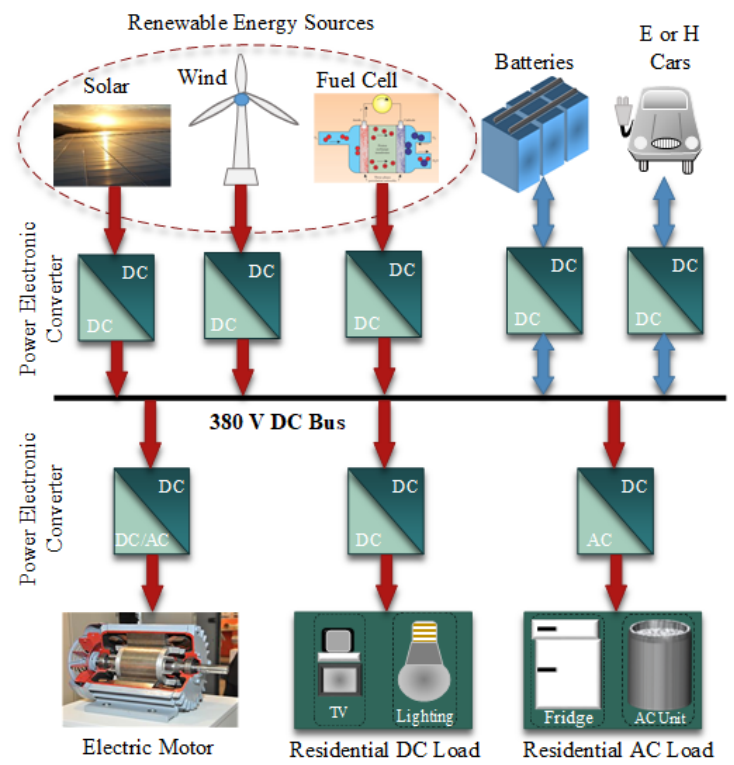

Fig. 1. The structure of a DC nanogrid 
increases the number of components, cost, and complexity [21]. A boost converter combined with flyback configuration is investigated in [22] for high conversion ratio applications. It is shown in Fig. 2 (a). The converter can attain high voltage gain, but winding utilization is limited. Moreover, the switch suffers from a voltage spike. Besides, diodes experience significant high voltage stresses. Considering these issues, a new enhanced topology is proposed for high step-up voltage conversion ratio to attain high efficiency, the low voltage stress on diodes, and reduced voltage spike across the switch. The converter operation in steady-state is described in the next session. The experimental evaluation is carried out in Section III. The conclusion based on results is drawn at the end.

\section{Steady-STAte Operation}

In this section, the proposed converter is studied theoretically in steady-state. The proposed converter is shown in Fig. 2 (b). The proposed topology comprises one active switch, three diodes, three capacitors, and a coupled inductor. A clamp circuit is integrated to suppress the switch voltage spike to improve the performance. The clamp diode is added in series between primary and secondary winding. This configuration stores leakage energy in a clamp capacitor and then directly moves to the output capacitor without intermediate storage. An intermediate capacitor with a diode multiplier is added in the proposed configuration to lift the conversion ratio of voltage and to further reduce the voltage stress.

The converter is analyzed in steady-state by making the following assumptions;

1. Capacitors are assumed larger so that their voltages are constant.

2. Switch and diodes are assumed ideal.

3. The magnetizing inductance of the coupled-inductor is $L_{m}$ and leakage inductance is $L_{k}$. The coupling coefficient is $k=L_{m} / L_{m}+L_{k}$.

The converter has portrayed five operating modes in steady-state under continuous conduction mode (CCM) operation. Some key waveforms are demonstrated in Fig. 3. The circuit in each operating mode is illustrated in Fig. 4.

Mode 1: The operation of this mode is shown in Fig. 4 (a). The switch is closed in this mode. The current in the leakage inductor is increasing linearly. The secondary side current is positive and decreasing. Energies stored in $C_{i}$ and $C_{c}$ continue to transfer to the output capacitor. Diode $D_{o}$ is forward- biased and diodes $D_{i}, D_{c}$ are reverse-biased. Diode $D_{o}$ turns off at a low rate of change of current; reverse recovery losses are minimized. Mode 1 terminated when the secondary side current becomes zero.

Mode II: The operation of this mode is shown in Fig. 4 (b). The magnetizing inductance current increases linearly. The magnetizing inductor is charged by dc source. The secondary winding current is negative. The intermediate capacitor is charged by input source through the coupled inductor. Diode $D_{i}$ is forward-biased and diodes $D_{o}, D_{c}$ are reverse-biased. The load is sustained by $C_{o}$. This mode is terminated when the switch is opened.

Mode III: The switch is opened. The clamp diode turns on and leakage energy move to $C_{c}$. The secondary side current is negative and diode $D_{i}$ is turned on. The load is driven by $C_{o}$. Diode $D_{i}$ turns off at a low rate of change of current; thus, reverse recovery losses are minimized. This mode is finished

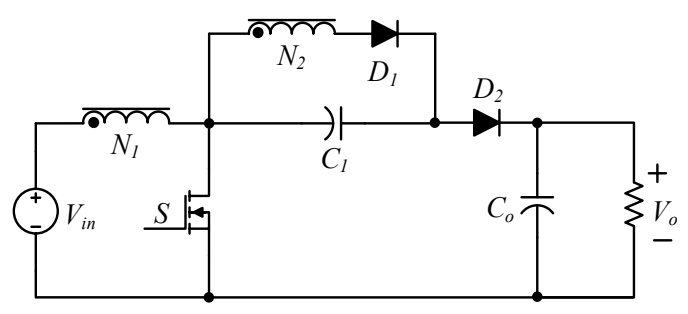

(a)

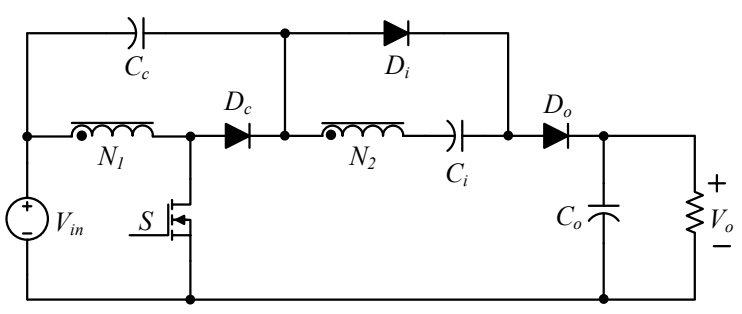

(b)

Fig. 2. (a) Boost-flyback integrated converter [22] (b) The proposed high step-up converter

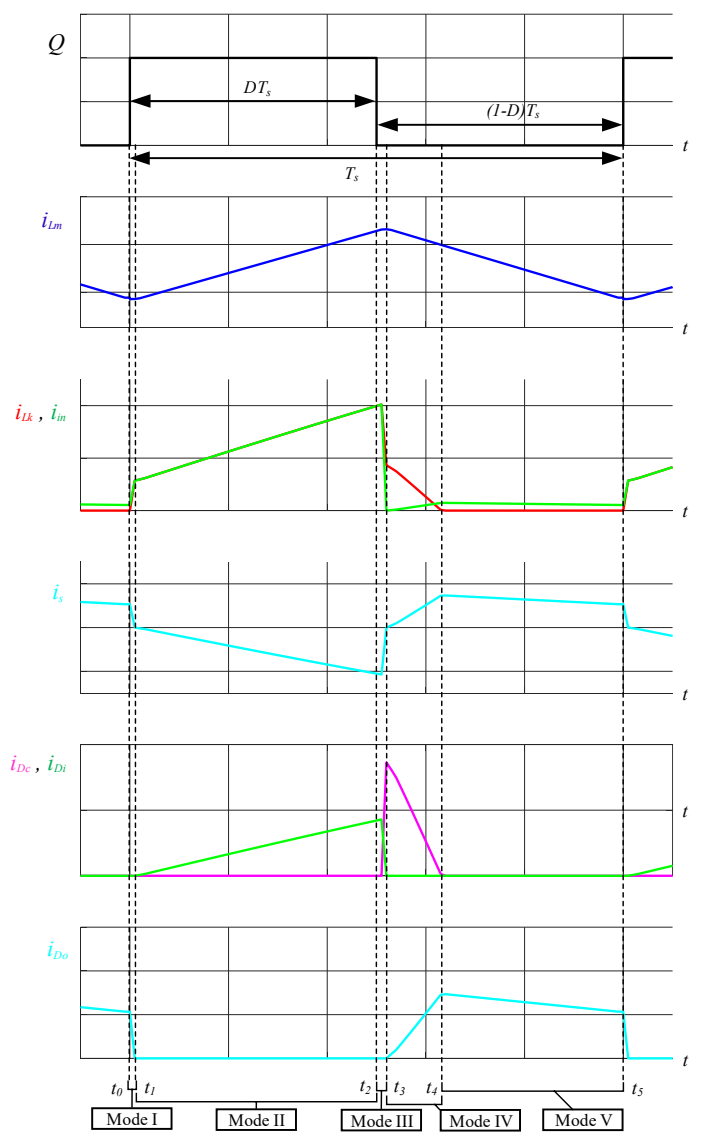

Fig. 3. Steady-state waveforms in CCM

when the secondary side current is zero.

Mode IV: The leakage energy continues to move to the clamp capacitor. The current in the secondary side is positive, so, diode $D_{i}$ reverse biased. Diode $D_{o}$ is forward biased. The stored energies in the magnetizing inductor and intermediate capacitor move to the output side, charging $C_{o}$. This mode is ended when all leakage energy is moved to the clamp capacitor. 
Mode $\mathrm{V}$ : Diode $D_{c}$ is reverse-biased because leakage energy is shifted to $C_{c}$. Magnetizing energy continues to transfer to output through the coupled inductor. The leakage stored energy in $C_{c}$ move to the output capacitor through the secondary winding of the coupled inductor. Diode $D_{o}$ remains on and diodes $D_{c}, D_{i}$ are reverse-biased. This mode is ended when the switch is closed.

The time duration of Mode I and III are very short; therefore, they are not considered in a steady-state analysis. Mode II, IV and V are considered in steady-state. The following circuit equations can be written in Mode II.

$$
\begin{gathered}
V_{1}^{I I}=k V_{\text {in }} \\
V_{L k}^{I I}=(1-k) V_{i n} \\
V_{2}^{I I}=V_{C i}=n k V_{i n}
\end{gathered}
$$

By applying the volt-second balance (VSB) principle on $L_{k}$, voltage across $L_{k}$ can be expressed as

$$
V_{L k}^{I V}=\frac{(1-k)(1+n)}{2(1-D)} D V_{i n}
$$

The output voltage in Mode $\mathrm{V}$ can be expressed as

$$
V_{o}=V_{\text {in }}+V_{C c}-V_{2}^{V}+V_{C i}
$$

By applying VSB on $L_{m}$, the following voltage equations are found;

$$
\begin{gathered}
V_{C c}=\frac{(1+k)+n(1-k)}{2(1-D)} D V_{i n} \\
V_{2}^{V}=\frac{-n k D}{(1-D)} V_{i n}
\end{gathered}
$$

By substituting (3), (6) and (7) into (5), the voltage gain of the proposed configuration is expressed as

$$
\frac{V_{o}}{V_{\text {in }}}=\frac{1}{1-D}\left[1+n k+\frac{(1-k)(n-1) D}{2}\right]
$$

The output voltage of the converter is a function of duty cycle and coupling coefficient of the coupled inductor. Fig. 5 illustrates the voltage gain under different values of the coupling coefficient. The leakage inductance of the coupled inductor degrades the voltage gain; however, its effect is very small. The ideal gain can be obtained by ignoring $L_{k}$ and setting $k=1$.

$$
\frac{V_{o}}{V_{\text {in }}}=\frac{1+n}{1-D}
$$

The proposed converter has a higher voltage gain compared to a single switch forward and flyback converters, which mainly utilize the transformer turns ratio for high conversion gain. Large transformer size results in higher leakage inductance and voltage stresses across devices resulting in lower conversion efficiency. A comparison of voltage gain is illustrated in Fig. 6 which shows that the proposed converter can achieve higher voltage gain than other single switch isolated converters. The voltage stresses on semiconductor devices are given by

$$
\begin{aligned}
& v_{d s}=V_{D c}=\frac{V_{o}}{1+n} \\
& V_{D i}=V_{D o}=\frac{n V_{o}}{1+n}
\end{aligned}
$$

The average current in each diode is $I_{o}$. The peak current stresses are given by

$$
i_{D i}=\frac{2 I_{o}}{D}
$$

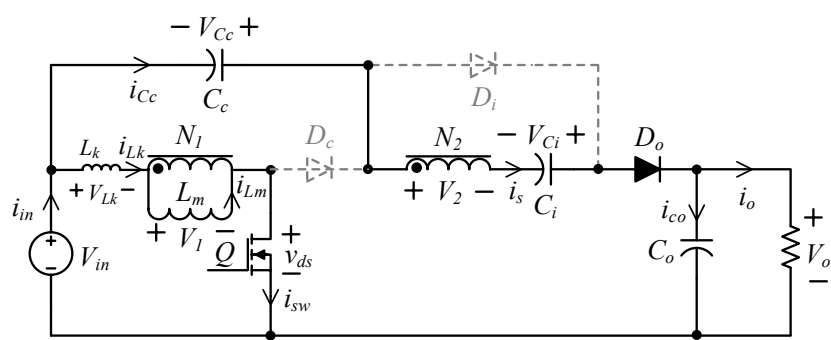

(a)

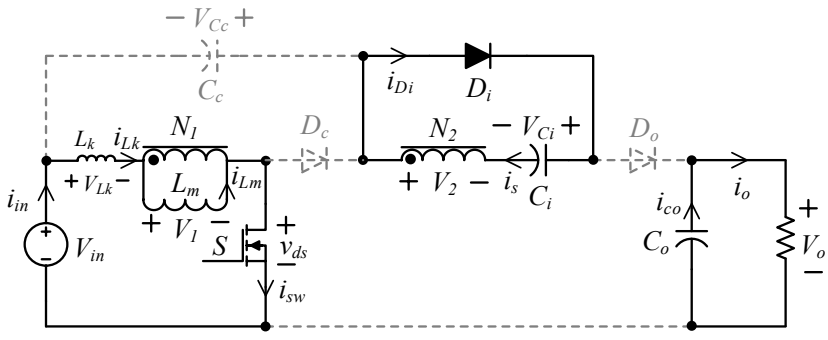

(b)

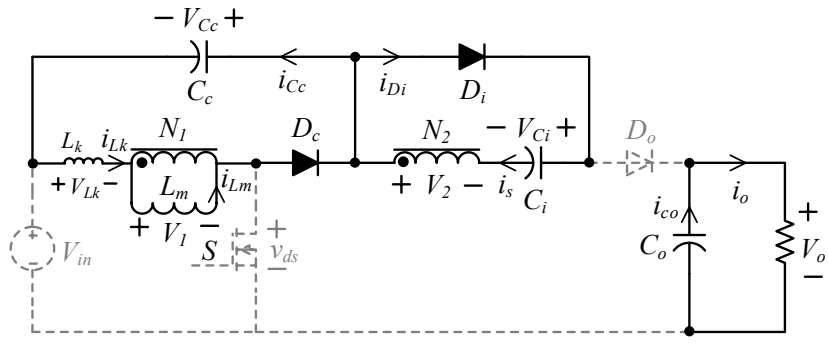

(c)

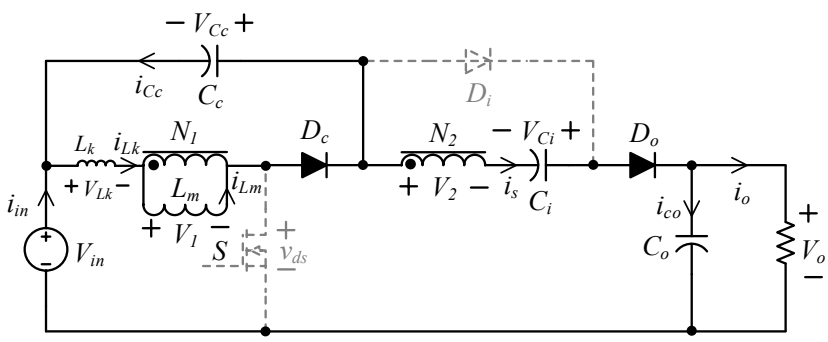

(d)

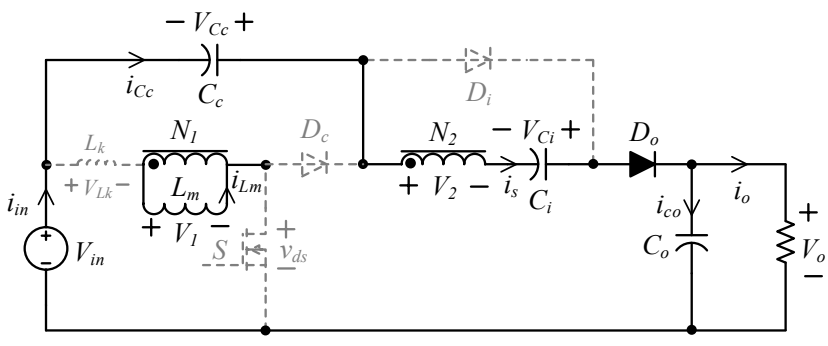

(e)

Fig. 4. Illustration of different operating modes; (a) Mode 1 (b) Mode II (c) Mode III (d) Mode IV (e) Mode V

$$
i_{D o}=\frac{2 I_{o}}{1-D}
$$

In Mode II, the switch maximum current can be written as

$$
i_{s w}=i_{L m}+n i_{D i}
$$




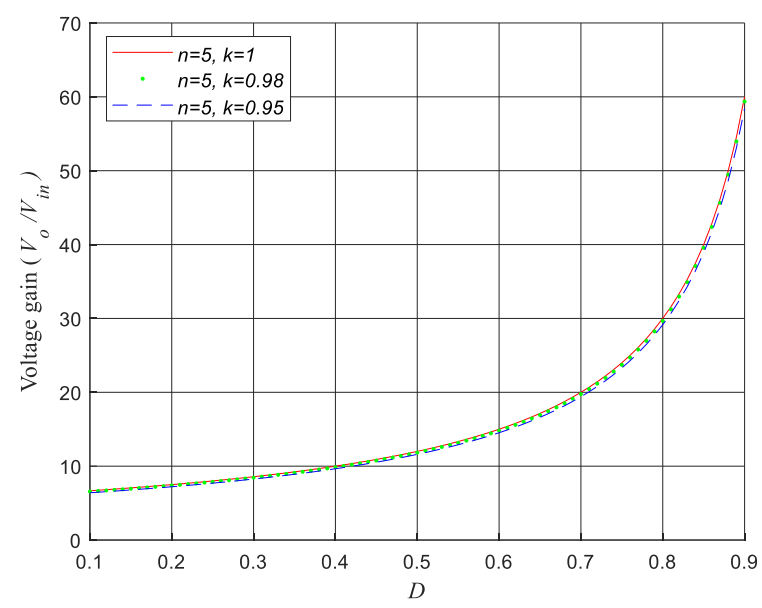

Fig. 5. Voltage conversion gain under different coupling coefficient

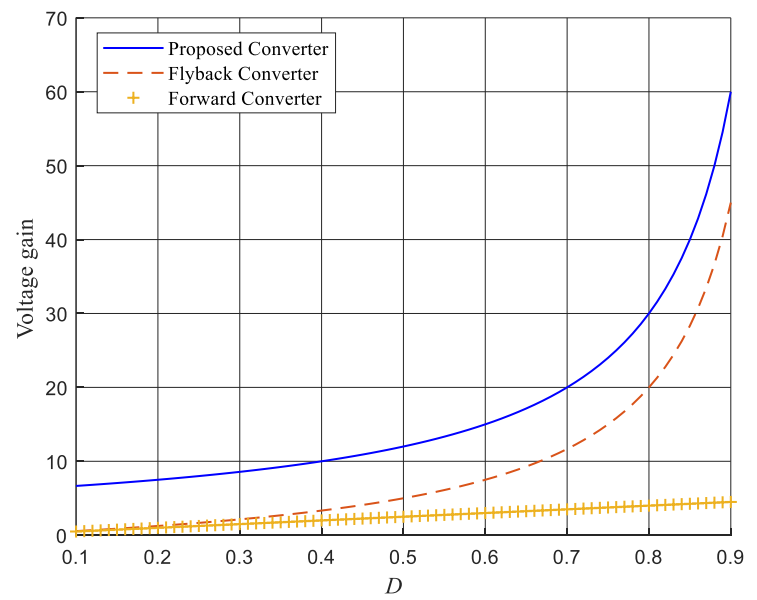

Fig. 6. A comparison of voltage conversion gain with single switch forward and flyback converters

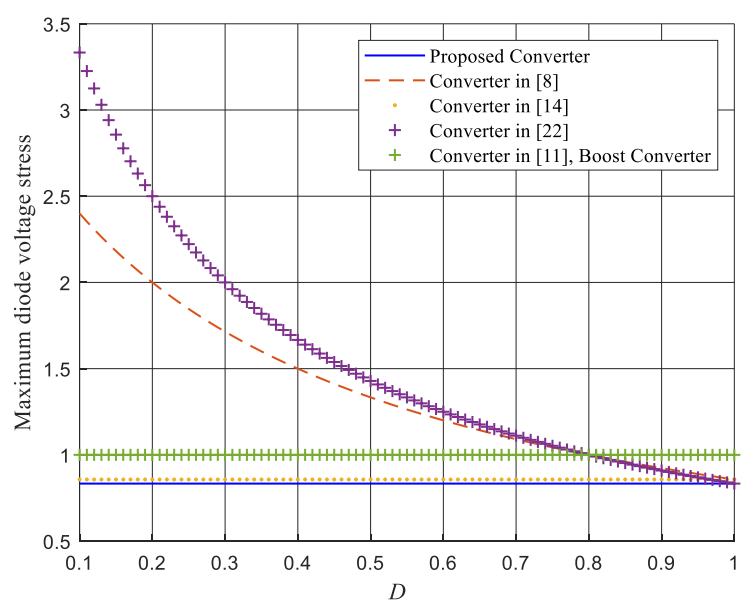

Fig. 7. Maximum diode voltage stress comparison

When the switch is turned off, switch maximum current flows through diode $D_{c}$. Thus, the peak current in the switch and diode $D_{c}$ is given by

$$
i_{s w}=i_{D c}=\frac{2 n+D-n D}{D(1-D)} I_{o}
$$

\section{A. Performance Comparison}

A comparison of the proposed topology with other topologies in terms of voltage conversion ability, voltage stresses, number of components and conversion efficiency is listed in Table I. The proposed converter has higher gain except [14]. However, the converter in [14] utilizes another inductor for resonates operation mode. The maximum diode voltage stress against duty cycle is illustrated in Fig. 7. The distinct feature of the proposed configuration is low voltage stress on diodes compared to other topologies. Moreover, the voltage stress doesn't vary with the duty cycle. The voltage stress on the switch is significantly lower than the output voltage. Thus, the switch with low voltage rating can be utilized to enhance the efficiency and to reduce the system cost.

TABLE 1

PERFORMANCE COMPARISON WITH OTHER CONVERTERS

\begin{tabular}{|c|c|c|c|c|c|}
\hline Converters & Proposed & [8] & [11] & [14] & [22] \\
\hline $\begin{array}{c}\text { No. of } \\
\text { components } \\
\text { (Switch/Core } \\
/ \\
\text { /Diodes/Cap } \\
\text { acitors) }\end{array}$ & $1 / 1 / 3 / 3$ & $1 / 1 / 3 / 3$ & $2 / 1 / 2 / 3$ & $1 / 2 / 3 / 3$ & $1 / 1 / 2 / 2$ \\
\hline Voltage Gain & $\frac{1+n}{1-D}$ & $\frac{2+n D}{1-D}$ & $\frac{1+n}{1-D}$ & $\frac{2+n}{1-D}$ & $\frac{1+n D}{1-D}$ \\
\hline $\begin{array}{c}\text { Maximum } \\
\text { diode } \\
\text { voltage } \\
\text { stress } \\
\end{array}$ & $\frac{n}{1+n} V_{o}$ & $\frac{1+n}{2+n D} V_{o}$ & $V_{o}$ & $\frac{1+n}{2+n} V_{o}$ & $\frac{n}{1+n D} V_{o}$ \\
\hline Efficiency & $97.1 \%$ & $97.4 \%$ & $96.9 \%$ & $97.4 \%$ & $95.15 \%$ \\
\hline
\end{tabular}

\section{EXPERIMENTAL RESULTS}

A $200 \mathrm{~W}$ prototype circuit is built in the laboratory. The prototype is tested to verify the theoretical analysis. The input voltage is set $30 \mathrm{~V}$ in the experiment and the output voltage is regulated at $380 \mathrm{~V}$. The switching frequency is $100 \mathrm{kHz}$. The nominal value of the duty cycle is set to 0.5 for optimal operation. The turns ratio is calculated from (9) according to the input and output voltages, which is designed at 5.4. The other key parameters and components used in the experiment are listed in Table II. The key converter waves of current and voltage are recorded to demonstrate the performance. Fig. 8 demonstrates the recorded experimental waveforms under full load condition in the laboratory. Fig. 8 (a) illustrates the PWM signal, output voltage, input voltage, and switch voltage stress.

TABLE II

DESCRIPTION OF COMPONENTS AND KEY CIRCUIT PARAMETERS

\begin{tabular}{|c|c|c|}
\hline Description & Parameters & Nominal Values \\
\hline Input Voltage & $V_{\text {in }}$ & $30 \mathrm{~V}$ \\
\hline Output Voltage & $V_{o}$ & $380 \mathrm{~V}$ \\
\hline Output Power & $P_{o}$ & $200 \mathrm{~W}$ \\
\hline Nominal Duty Cycle & $D$ & 0.5 \\
\hline Switching Frequency & $f_{s}$ & $100 \mathrm{kHz}$ \\
\hline Magnetizing Inductor & $L_{m}$ & $48 \mu \mathrm{H}$ \\
\hline Turns Ratio & $n\left(N_{2}: N_{1}\right)$ & 5.4 \\
\hline Coupled Inductor & ETD-44 & Ferrite Core \\
\hline MOSFET & $Q$ & $\begin{array}{c}\text { IPB027N10N5 }(100 \mathrm{~V}, 2.7 \\
\mathrm{m} \Omega)\end{array}$ \\
\hline Clamp Diode & $D_{c}$ & STPS30SM100S \\
\hline Diodes & $D_{i}, D_{o}$ & VS-15ETL06-M3 \\
\hline Capacitors & $C_{c}, C_{i}$ & $40 \mu \mathrm{F} / 250 \mathrm{~V}$ \\
\hline Output Capacitor & $C_{o}$ & $470 \mu \mathrm{F} / 450 \mathrm{~V}$ \\
\hline
\end{tabular}




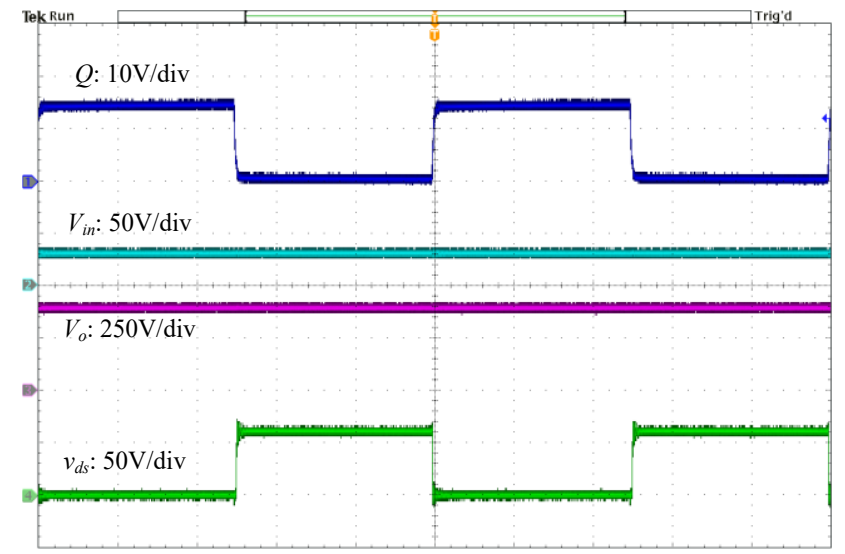

(a)

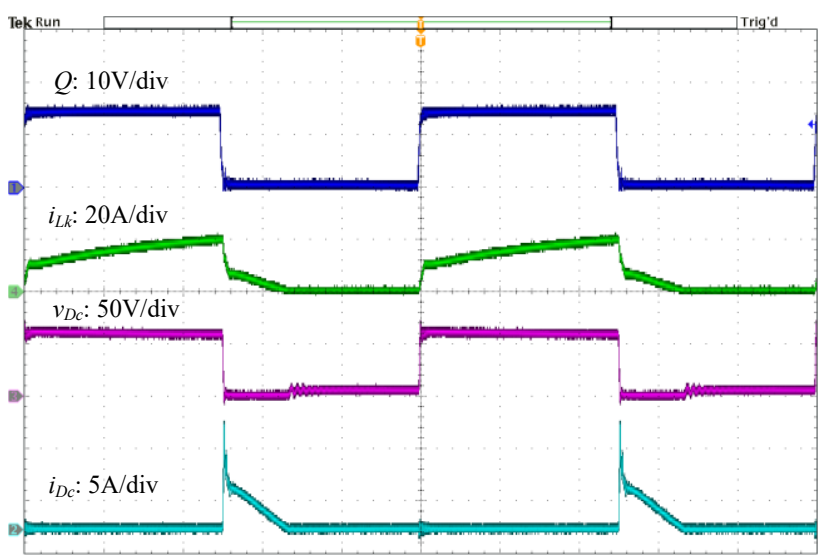

(b)

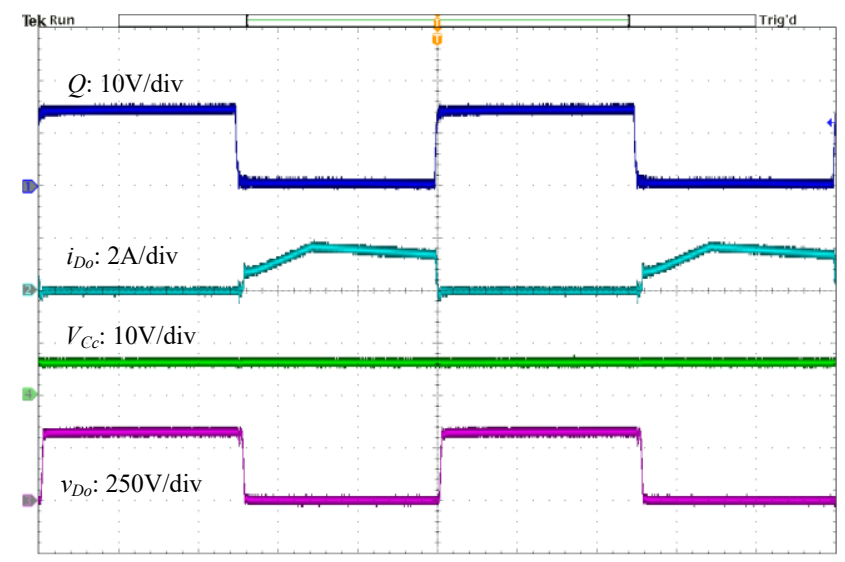

(c)

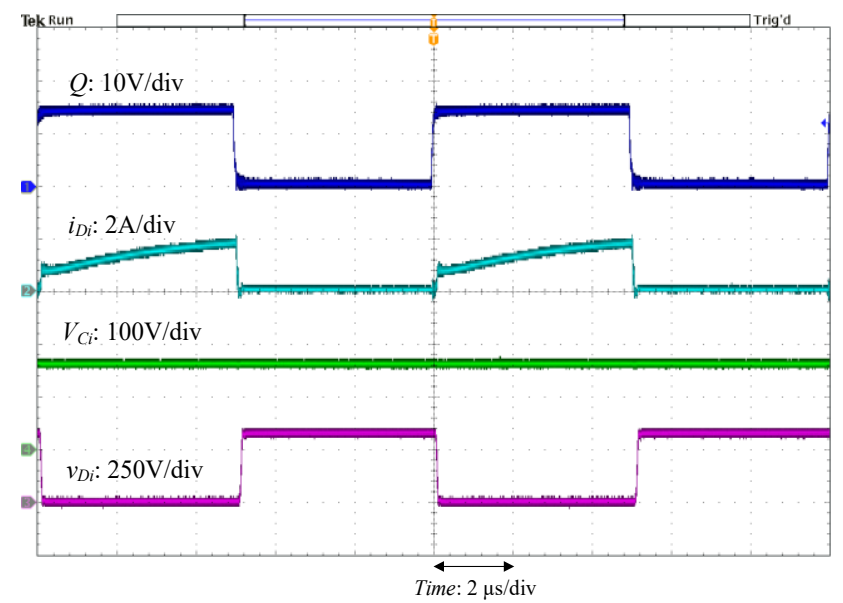

(d)

Fig. 8. Experimental results at full load

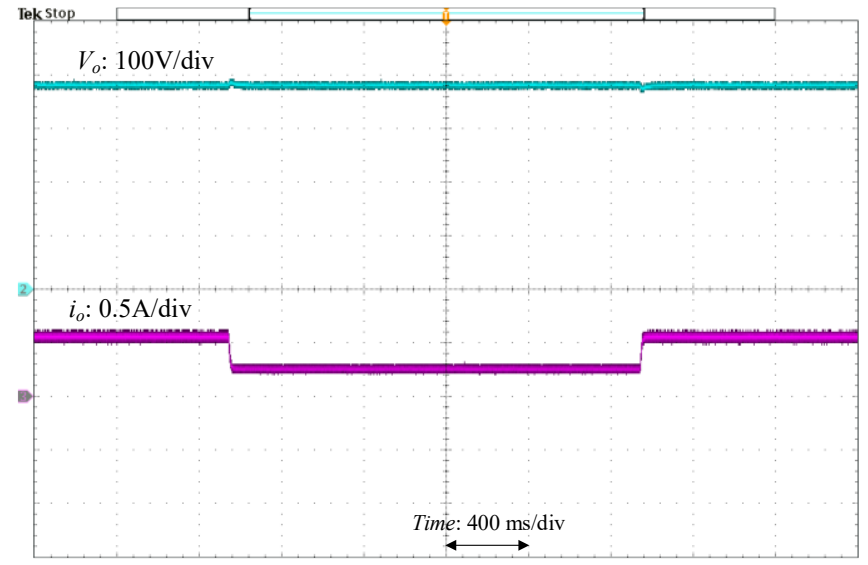

Fig. 9. Dynamic response of the proposed converter

The voltage stress is observed around $60 \mathrm{~V}$, which is almost $1 / 6^{\text {th }}$ of $V_{o}$. No ringing or voltage spike is noticed. Therefore, a low voltage rated switch is utilized to improve efficiency. The output voltage changes with $D$ as computed theoretically in (9). Fig. 8 (b) depicts the voltage and current of diode $D_{c}$, and current of leakage inductor. The leakage inductor current becomes zero when all leakage energy is released to $C_{c}$. The measured waveforms are uniform with the simulation results. Fig. 8 (c) shows the voltage and current of diode $D_{o}$, and the voltage across capacitors $C_{c}$. Fig. 8 (d) shows the voltage and current of diode $D_{i}$, and the voltage across capacitors $C_{i}$. The diodes current and voltage waveforms agree with the simulation results. All experimental waveforms are consistent with the simulation results and theoretical analysis. The dynamic response with the change in output load is shown in Fig. 9. The output voltage is constant with change in output power. The conversion efficiency of the converter is shown in Fig. 10. The efficiency changes with the load and converter obtain peak efficiency of $97.10 \%$. Single switch isolated converters such as forward and flyback converters experience high voltage stresses and spikes due to the large size of the transformer; therefore, their conversion efficiencies are lower. A power loss analysis is performed as described in [19]; therefore, it is not explained here. The losses of each component are calculated in order to identify lossy elements. The percentage loss distribution is shown in Fig. 11. It indicates that switch and coupled inductor losses are dominant compared to other components losses. The switch contributes to major losses due to hard switching at high frequency. The coupled inductor contributes the second major portion in power losses. For the prototype testing, ETD 44 core and copper wires are used. The design of coupled inductor can be optimized for mass production. The optimal core material for high frequency results in lower core losses. Moreover, highfrequency losses associated with coupled inductor can be reduced by using Litz wire. The European Efficiency (EU) and California Energy Commission efficiency (CEC) are also calculated to evaluate the effectiveness of the proposed topology for PV applications. All measured efficiencies are tabulated in Table III. The converter demonstrates a flat efficiency pattern which promises its performance for renewable energy applications.

TABLE III

PRototype MEASURED EFFICIENCIES

\begin{tabular}{|c|c|c|c|c|}
\hline $\begin{array}{c}\text { Efficiencies } \\
(\eta)\end{array}$ & Peak & CEC & EU & Full load \\
\hline $\begin{array}{c}\text { Measured } \\
\text { Values }\end{array}$ & $97.10 \%$ & $96.64 \%$ & $96.28 \%$ & $96.36 \%$ \\
\hline
\end{tabular}




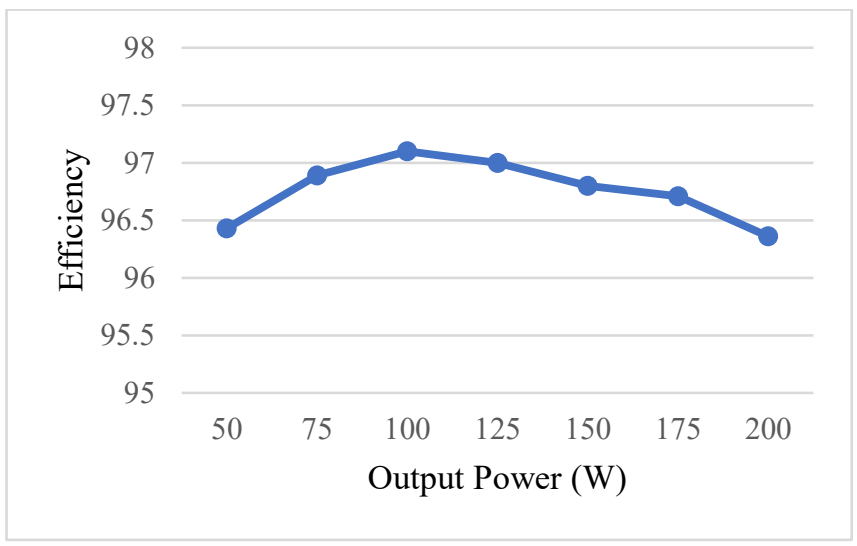

Fig. 10. The prototype conversion efficiency

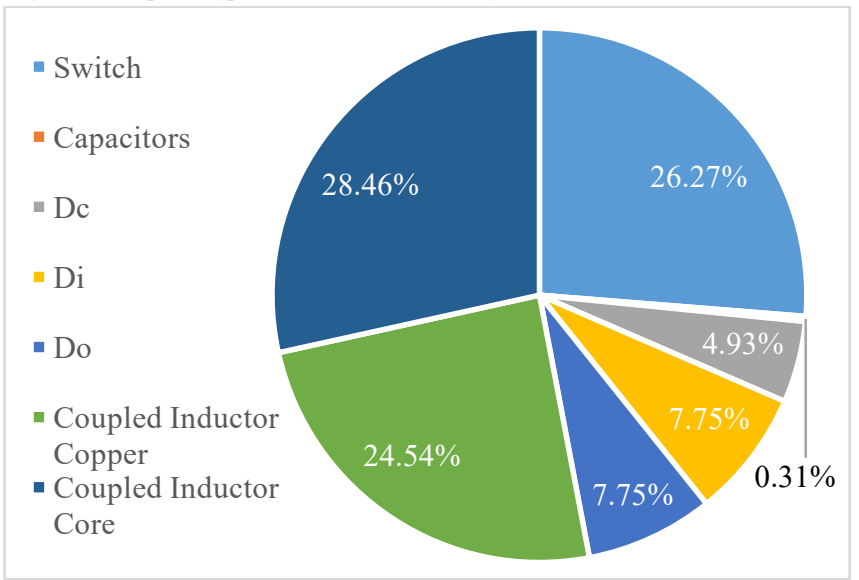

Fig. 11. Percentage loss distribution at full load

\section{CONCLUSION}

A high step-up dc-de converter has been investigated in this research for renewable energy-based DC nanogrid. The converter utilizes the technique of the coupled inductor to obtain high conversion ratio, high efficiency and reduced stresses of voltage across devices. The switch voltage stress is notably minimized which is measured $15 \%$ of the output voltage. This enables designers to choose a low rating MOSFET to further decreases losses thus enhancing efficiency. Furthermore, the reveres recovery related losses are reduced due to the leakage inductor. A prototype is constructed and tested in the laboratory to validate the claimed advantages. The converter has shown the advantage of high efficiency and low voltage stress meanwhile achieving high conversion ratio of voltage. The converter has demonstrated its potential for high boost applications, e.g. DC nanogrid.

\section{REFERENCES}

[1] Z. Ma, A. Pesaran, V. Gevorgian, D. Gwinner, and W. Kramer, "Energy storage, renewable power generation, and the grid: NREL capabilities help to develop and test energy-storage technologies," IEEE Electrification Magazine, vol. 3, no. 3, pp. 30-40, 2015.

[2] M. Shahidehpour, Z. Li, W. Gong, S. Bahramirad, and M. Lopata, "A Hybrid ac $\backslash$ dc Nanogrid: The Keating Hall Installation at the Illinois Institute of Technology," IEEE Electrification Magazine, vol. 5, no. 2, pp. 36-46, 2017.

[3] L. Schmitz, D. C. Martins, and R. F. Coelho, "Generalized high stepup DC-DC boost-based converter with gain cell," IEEE Transactions on Circuits and Systems I: Regular Papers, vol. 64, no. 2, pp. 480-493, 2017.

[4] M. Forouzesh, Y. P. Siwakoti, S. A. Gorji, F. Blaabjerg, and B. Lehman, "Step-up DC-DC converters: a comprehensive review of voltage-boosting techniques, topologies, and applications," IEEE Transactions on Power Electronics, vol. 32, no. 12, pp. 9143-9178, 2017.

[5] R. Hasan, S. Mekhilef, M. Seyedmahmoudian, and B. Horan, "Gridconnected isolated PV microinverters: A review," Renewable and Sustainable Energy Reviews, vol. 67, pp. 1065-1080, 2017.

[6] Y.-C. Hsieh, M.-R. Chen, and H.-L. Cheng, "An interleaved flyback converter featured with zero-voltage transition," IEEE Transactions on Power Electronics, vol. 26, no. 1, pp. 79-84, 2011.

[7] H. Liu, H. Hu, H. Wu, Y. Xing, and I. Batarseh, "Overview of highstep-up coupled-inductor boost converters," IEEE Journal of Emerging and Selected Topics in Power Electronics, vol. 4, no. 2, pp. 689-704, 2016.

[8] W. Yu et al., "High efficiency converter with charge pump and coupled inductor for wide input photovoltaic AC module applications," in Proc. IEEE ECCE, Sep. 2009, pp. 3895-3900.

[9] S. Sathyan, H. M. Suryawanshi, B. Singh, C. Chakraborty, V. Verma, and M. S. Ballal, "ZVS-ZCS high voltage gain integrated boost converter for DC microgrid," IEEE Transactions on Industrial Electronics, vol. 63, no. 11, pp. 6898-6908, 2016.

[10] Forouzesh, M., Shen, Y., Yari, K., Siwakoti, Y.P., and Blaabjerg, F., 'High-Efficiency High Step-up Dc-Dc Converter with Dual Coupled Inductors for Grid-Connected Photovoltaic Systems', IEEE Transactions on Power Electronics, 2018, 33, (7), pp. 5967-5982.

[11] Y. Zhao, W. Li, and X. He, "Single-phase improved active clamp coupled-inductor-based converter with extended voltage doubler cell," IEEE Transactions on Power Electronics., vol. 27, no. 6, pp. 28692878, Jun. 2012.

[12] W. Hassan, D. D.-C. Lu, and W. Xiao, "Analysis and Experimental Verification of a Single-Switch High Voltage Gain ZCS DC-DC Converter," IET Power Electronics, vol. 12, no. 8, pp. 2146-2153, July 2019. DOI: 10.1049 /iet-pel.2019.0076

[13] J. Ai and M. Lin, "Ultralarge gain step-up coupled-inductor dc-dc converter with an asymmetric voltage multiplier network for a sustainable energy system," IEEE Transactions on Power Electronics, vol. 32, no. 9, pp. 6896-6903, 2017.

[14] B. Gu, J. Dominic, J.-S. Lai, Z. Zhao, and C. Liu, "High boost ratio hybrid transformer DC-DC converter for photovoltaic module applications," IEEE Transactions on Power Electronics., vol. 28, no. 4, pp. 2048-2058, 2013.

[15] J.-H. Lee, T.-J. Liang, and J.-F. Chen, "Isolated coupled-inductorintegrated DC-DC converter with nondissipative snubber for solar energy applications," IEEE Transactions on Industrial Electronics, vol. 61, no. 7, pp. 3337-3348, 2014.

[16] W. Hassan, S. Gautam, D. Lu, and W. Xiao, "Analysis, Design, and Experimental Verification of High Step-up DC-DC Converter to Interface Renewable Energy Sources into DC Nanogrid," in 2019 IEEE International Conference on Industrial Technology (ICIT), Melbourne, 2019: IEEE, pp. 1649-1654. DOI: 10.1109/ICIT.2019.8755184

[17] Y. P. Siwakoti and F. Blaabjerg, "Single Switch Nonisolated UltraStep-Up DC-DC Converter with an Integrated Coupled Inductor for High Boost Applications," IEEE Transactions on Power Electronics, vol. 32, no. 11, pp. 8544-8558, 2017.

[18] M. Forouzesh, K. Yari, A. Baghramian, and S. Hasanpour, "Singleswitch high step-up converter based on coupled inductor and switched capacitor techniques with quasi-resonant operation," IET Power Electronics, vol. 10, no. 2, pp. 240-250, 2017.

[19] W. Hassan, D. D.-C. Lu, and W. Xiao, "Single Switch High Step-Up DC-DC Converter with Low and Steady Switch Voltage Stress," IEEE Transactions on Industrial Electronics, vol. 66, no. 12, pp. 9326-9338, Dec. 2019. DOI: 10.1109/TIE.2019.2893833

[20] Y. Ye, K. Cheng, and S. Chen, "A High Step-up PWM DC-DC Converter with Coupled-Inductor and Resonant Switched-Capacitor," IEEE Transactions on Power Electronics, vol. 32, no. 10, pp. 7739$7749,2017$.

[21] Y. Zheng, W. Xie and K. M. Smedley, "Interleaved High Step-Up Converter With Coupled Inductors," IEEE Transactions on Power Electronics, vol. 34, no. 7, pp. 6478-6488, 2019. doi: 10.1109/TPEL.2018.2874189

[22] W. Hassan, D. Lu, and W. Xiao, "Optimal Analysis and Design of DCDC Converter to Achieve High Voltage Conversion Gain and High Efficiency for Renewable Energy Systems," in 2018 IEEE 27th International Symposium on Industrial Electronics (ISIE), Cairns, Australia, 2018: IEEE, pp. 439-444. DOI: 10.1109/ISIE.2018.8433857 